\title{
A New Thermostat for Real-Time Price Demand Response: Cost, Comfort and Energy Impacts of Discrete-Time Control Without Deadband
}

\author{
David P. Chassin ${ }^{\mathrm{a}, \mathrm{b}, *}$, Jakob Stoustrup ${ }^{\mathrm{b}}$, Panajiotis Agathoklis ${ }^{\mathrm{a}}$, \\ Nedjib Djilali ${ }^{\mathrm{a}}$ \\ ${ }^{a}$ University of Victoria, Victoria, British Columbia, Canada \\ ${ }^{b}$ Pacific Northwest National Laboratory, Richland, Washington, USA
}

\begin{abstract}
Thermostatically controlled electrical loads can provide valuable energy storage and are prime candidates for fast acting demand response (DR) that can be used to mitigate highly variable renewable power generation and limited availability of ramping resources. When conventional thermostats are retrofitted for real-time price DR control, significant control errors can arise, particularly in the form of dispatch control drift. This paper identifies the underlying causes and presents a new residential thermostat design that enables accurate aggregate load control. The new design gives rise to linear time-invariant models of aggregate load control and demand response, which facilitate the design of highly accurate load-based regulation services for electricity interconnections. Detailed simulation and performance studies coupling a residential house and feeder models are presented to show how consumer comfort and cost savings are achieved and how energy use is impacted for cities in three different climatic zones. During peak times, the new thermostat imparts the entire residential load an energy demand elasticity of about $10 \%$ to $25 \%$. Larger demand elasticities could be achieved by extending the control strategy to other residential thermostatic loads. The proposed thermostat design can operate in the real-time distribution capacity auction system and can provide all the benefits associated
\end{abstract}

*Corresponding author: david.chassin@pnnl.gov

Preprint submitted to Elsevier

June 20, 2015 
with transactive systems, and in particular facilitate increased integration of renewable resources.

Keywords: Retail electricity market, renewable integration, real-time pricing, demand response, transactive control

\section{Introduction}

Demand response is increasingly regarded as an important resource for electricity interconnections in industrialized economies. Demand response provides both economic and technical benefits that far outweigh their costs [1]. The United States Federal Energy Regulatory Commission issued FERC Order 745 specifically to encourage participation and ensure the competitiveness of demand resources in organized wholesale markets [2]. In spite of the regulatory setback dealt by the US Court of Appeal's decision to vacate the order[3], both proponents and critics of FERC's approach agree that demand plays a crucial role in mitigating both the market power of electricity suppliers [4] and the intermittency of renewable generation resources [5] while maintaining the comfort and satisfaction of consumers [6].

Research into fast-acting demand response was originally motivated by technical pressures to improve system efficiency while retaining a high level of consumer satisfaction. Direct load control and time-of-use demand response strategies have been widely used for decades but often show limited benefits at subhourly levels [7]. To address these limitations market-based real-time demand response based on microeconomic theory [8] was initially demonstrated in computer resource allocation [9] and proposed for electricity operations [10]. Work on multi-commodity flow [11] and building thermal control [12] demonstrated the applicability of markets to optimal micro-allocation problems in energy. In all these approaches, markets are used to find short-term Pareto-optimal allocations of a constrained resource in a technical system by determining the short-term price at which the supply equals demand over the coming interval of time. Individual responsive system components are equipped with new control 
elements to bid for resource utililization to satisfy consumer needs and respond to changes in price by changing resource usage in the short term. The benefits of this approach have been shown to reach throughout electric interconnections including enhancing the penetration of intermittent renewable resources [13].

However, incentives, dispatch methods and compensation of demand response remain challenges that restrain system planners and operators from adopting these fast-acting control strategies. Hogan [14] argues that the "the ideal and economically efficient solution regarding demand response compensation is to implement retail real-time pricing at the LMP, thereby eliminating the need for [wholesale] demand response [compensation]." To investigate the technical questions regarding the large-scale feasibility of near real-time demand response the US Department of Energy funded the 2006 Olympic Peninsula [15] and 2013 Columbus Ohio [16] demonstration projects. Both projects sought to address the open technical questions regarding the so-called "price-to-devices" challenge [17] by demonstrating the transactive control approach on retrofitted control equipment that integrates small-scale residential, commercial and municipal electrical equipment with utility electric power distribution system operations as a first step toward integrating distributed generation and demand response into wholesale operations. "Transactive control" in this context refers to a distributed resource allocation strategy that engages both electricity suppliers and consumers using market-based mechanisms extending down to the retail level for the purpose of enabling demand response by the utilities at the wholesale level [18].

This paper addresses potentially significant shortcomings of the existing conventional thermostat control retrofits uncovered by the demonstration projects. Specifically, under certain circumstances the demand response quantity dispatched by the retail markets using the real-time price was not sustained for the entire duration of the market clearing interval. In addition, any significant sustained deviation in the price could lead to unpredictable demand response deviations because of changes in the diversity of thermostatic device states. These problems lead to increased uncertainty about the reliability demand re- 
sponse services based on conventional thermostats and lack of confidence in the effectiveness of demand response control systems. These shortcomings are mitigated by a fundamental redesign of residential thermostats when used for fast-acting demand response. In particular the new thermostat eliminates the use a deadband altogether and imposes a discrete-time control model instead. These steps seem to individually violate conventional wisdom about how thermostat should work, i.e., 1) deadbands are necessary to avoid fast cycling of heating/cooling equipment and 2) discrete-time control results in excessive overshoot and degrades consumer comfort. However taken together they represent a novel solution to the problem of obtaining accurate large-scale fast-acting demand response from residential energy systems. After reviewing the background of the transactive control problem, this paper reports the preliminary results of those investigations.

Without mechanisms like transactive control, price-responsive load requires directly engaging a very large number of very small participants in the unitcommitment and economic dispatch process [19]. The computational complexity of the centralized optimal dispatch problem makes this impractical for anything more than the thousands of larger suppliers already involved [20]. Strategies extant for addressing this challenge generally involve retail demand aggregation that enables the integration of demand units by proxy of a reduced number of larger representative units. Private entities such as Enernoc have based their business models on this approach. These are used primarily on commercial buildings where the control systems are more amenable to this integration and the number of control points per Watt of resource is lower than it is for residential buildings. Unfortunately, this leaves nearly half the available building load untapped as a demand resource for utilities.

Previous demand response through heating/cooling system control has generally focused on retrofits to existing thermostats. Rather than fundamentally rethinking the operation of thermostats, these retrofit strategies added new capabilities to thermostats to enable demand response behavior needed by utilities for peak load reduction or shifting. Most of these methods are focused on direct 
load control design either for peak load reduction [21] [22] or for regulation services [23] [24]. Indirect load control methods are typically extensions of direct load control methods that include additional control component to convert incentive signals such as prices to comfort signals such as thermostat offsets [15] $[16]$.

Using markets to solve electricity resource allocation problems at the wholesale bulk system level is well-understood [25]. But transactive control takes the idea to the retail level by solving the resource allocation problem at the distribution level first before integrating it at the wholesale level. These retail markets are designed to find an allocation of distribution capacity, distributed generation and demand response to resolve how much wholesale energy resource is required and determine how much distributed generators should produce and customers can consume in the coming time interval. Transactive control systems use sub-hourly distribution capacity markets to determine energy prices that minimizes the imbalance between supply and demand for electricity for participating equipment during the next operating interval [26]. These systems compute 5-minute retail real-time prices (RTP) for energy that reflect the underlying wholesale LMP plus all other distribution costs and scarcity rents arising from distribution constraints. In cases where large amounts of renewable resources are available the real-time price can be less than the LMP. Negative prices are even possible when a surplus of must-run generation is available. The RTP comes under a new tariff presumably designed to be revenue neutral in the absence of demand response.

Distributed generation, load shifting, demand curtailment, and load recovery can all be induced by variations in real-time prices. Given these responses transactive control systems can reduce the utility's long-term exposure to price volatility in the wholesale market and the costs of congestion on the distribution system [27]. These can reduce the long-term average cost of energy for consumers who are willing to forgo consumption in the very short-term. Shortterm retail prices are discovered using a feeder capacity double auction and these prices can help manage distribution, transmission or bulk generation level 
constraints. Distributed generation and demand response are dispatched based on consumers' preferences, which they enter into an advanced thermostat that acts on their behalf as an automated agent bidding for electricity. Transactive thermostats both bid for the electricity and modulate consumption in response to the market clearing price. By integrating this response to a price signal that reflects anticipated scarcity, the system closes the loop on energy delivery and improves resource allocation efficiency by ensuring that consumers who value the power most are served prior to those who are willing to forgo it for a short time. At the same time, consumers provide valuable services to the wholesale bulk power system [13] and experience reduced energy costs at times of day when they express preferences for savings over comfort.

The overall approach used in the paper to develop and deploy transactive control systems may appear simple. But this is quite deceptive because although the individual components of the system are indeed very simple in their design and operation, their combined behavior is quite complex to model and well beyond the capabilities of the existing modeling and simulation tools used to study demand response systems [28]. In Section 2 we examine the new thermostat to reveal how the undesirable behavior of existing thermostats is eliminated and the desired behavior is introduced. In Section 3 we discuss the numerical models used to study the aggregate behavior the controlled loads and we discuss the results and findings obtained from the simulations in Section 4. As we will show, this new thermostat design is at once simpler than existing thermostats because it does not have any hysteresis and provide synchronized discrete-time responses, but also much more effective at providing demand response control services that utility can aggregate to provide capacity and ramping resources that have real value in wholesale electricity markets.

\section{New Thermostat Design}

The proposed thermostat design shown in Figure 1 follows the general paradigm used for all transactive control systems developed to date. Three inputs are provided to a thermostat. The consumer's indoor air temperature setpoint $T_{D}$ and 
comfort preference $k$ are set every few hours from an occupancy schedule established by the consumer. The real-time price $P_{C}$ is sent by the utility every 5 minutes and is derived from various sources such as the hourly wholesale energy price signal, the real-time imbalance, and local capacity constraint prices, if any. The price signal is then filtered to separate the component with a time-constant that matches the building mass response and a time-constant that matches the air's response, denoted as the slow response and fast response components, respectively. Both of these signals are then converted to a temperature offset using the consumer's comfort preferences. The slow response temperature offset signal compared to the estimated mass temperature $T_{M}$ (the design of which is not in the scope of this paper) and added to the offset from the fast response signal. These are added to the consumer's desired temperature setpoint $T_{D}$, which is finally compared to the observed indoor air temperature $T_{A}$ to determine the control temperature $T_{C}$. The signal is updated only when a new price received, which in the current embodiment is once every 5 minutes.

Once the control temperature $T_{C}$ is determined, the remainder of the system is implemented in a manner that is consistent with conventional thermostats, and thus could be used to replace existing thermostat without changing the design of the rest of the HVAC system. The only difference with conventional thermostats systems is that the controller output $M$ is a discrete-time signal rather than a continuous-time signal.

This design recognizes that a house has two fundamental responses, a fast one for the air and a slow one for the mass. In addition, it recognizes that any price signal from the utility may have multiple components, including a short term price signal emanating from distribution capacity or ancillary service markets, and a long term price signal from bulk energy markets. The purpose of the new thermostat is to control the long-term response of the house based on the bulk energy price independently of the short-term response of the house, which is based on the short-term distribution capacity or ancillary services price signal.

There are other possible responses that are not controlled by this design, such as the ramping response. At this time the price signals are not expected 
to arrive frequently enough (e.g., $t_{s}<1$ minute) to allow control of a house's ramp response anyway. Such signals are not expected to include any primary regulation components for the foreseeable future. So both this signal and the associated ramp response are not addressed in this paper.

Only the fast-response controller is studied in this paper. The controller is based on the Olympic controller design except that it uses a high-pass filter to remove the super-hourly components of price variations, and sets the deadband to zero while maintaining the controller output signal for the duration of the market interval.

\subsection{Methods and Simulations}

The Olympic and Columbus demonstration project were successful in achieving their primary objectives: 1) they shown the effectiveness of using price signals to manage peak loads using demand resources and 2) they showed that consumers could retain control while providing the resources necessary to accomplish the former. In addition they showed that financial benefits accrue to both the utilities who installed and the consumers who participated in the program.

In both projects, the demand curves were constructed from the bids received from the responsive equipment in households subject to the RTP tariff, as shown in Figure 2 (left). Unresponsive load corresponds to all the other load on the feeder, including unresponsive equipment under RTP tariff, all other customers on non-RTP tariffs, services and losses. Bids were computed by the thermostats based on measurements of the indoor air temperature such that

$$
P_{B}=\frac{k P_{D}}{T_{M}-T_{D}}\left(T_{A}-T_{D}\right)+P_{A}
$$

where $P_{A}$ is the long-term average price over the past 24 hours, $P_{B}$ is the bid price, $P_{D}$ is the long term price standard deviation, $k$ is the customer's comfort control setting, $T_{A}$ is the measured indoor air temperature, $T_{D}$ is the customer's desired indoor air temperature, and $T_{M}$ is the maximum cooling $\left(T_{H}\right)$ or minimum heating $\left(T_{L}\right)$ indoor air temperature allowed. The quantity 
$T_{M}-T_{D}$ is referred to as the demand response control gain or comfort gain in $\$ /^{\circ} \mathrm{F}$, which is illustrated for cooling in Figure 2 (right).

The supply curve was constructed from bids received by the various resources available, although in the case of the Columbus demonstration there was only the feeder supply. In the Olympic demonstration, supply included distributed generation with "hot" capacity representing must-run units that are already running and presumably can't or won't stop and any units that have zero marginal production cost, such as photovoltaic units. So called "cold" units are those that have start-up costs included in the marginal cost and therefore are held off until the demand is sufficiently high to justify starting them.

In all existing embodiments of the transactive control system the clearing price $P_{C}$ and quantity $Q_{C}$ are found at the intersection of the supply and demand curves. The clearing price is then used to change the thermostat setpoint such that

$$
T_{C}=T_{D}+K^{-1}\left(P_{C}-P_{A}\right)
$$

as shown in Figure 2 (right). The thermostat then changes the mode of the HVAC system according to the relationship between the $T_{A}$ and $T_{C}$ in the conventional manner based on whether the value of $T_{D}$ is based on the heating or cooling setpoint.

\section{Numerical Methods}

Detailed simulations of load control using thermostats confirmed some potentially significant technical problems that were anecdotally observed in these embodiments of the transactive control system. Among these was demand response dispatch control drift. When the markets cleared the measured load was initially very close to the cleared load. However, during the five minutes that followed, before the next market clearing, the total load drifted away from the cleared load. In the demonstations, this was observed as a deviation in the actual energy use over the 5-minute interval from the expected energy use.

This deviation suggests that the 5-minute market implemented did not work well as a load dispatch "control" system. The prevailing hypothesis is that the 
drift is the result of changes in the diversity of thermostat states induced by a common exogenous signal. These changes in the state diversity of the loads were caused by the aggregate load's initial response to the change in price [29], as shown in Figure 3 (top). Because diversity always increases in the absence of an external forcing signal, the aggregate load approaches the equilibrium diversity load given the initial price signal and the prevailing conditions at the time the load is being observed. Under peak load conditions, this drift can be very significant, as illustrated in Figure 3 (bottom), and can only be mitigated by a) minimizing the degree to which diversity is affected by control signals, or b) preventing the devices from changing state during the 5 minute interval between price clearings. Because option (a) would defeat the purpose of the load control system, it would seem if diversity changes are the cause of the problem then option (b) is the only mitigation strategy available.

The overall structure of the real-time price demand response simulations used to study the proposed solution is illustrated in Figure 4 (left). For each study the location, house design specifications and tariff are used to produce a single house model, the performance of which is observed using thermostat and metering telemetry. At the utility level, a feeder is simulated with realtime pricing based on the transactive control system used in the Olympic and Columbus projects as shown in Figure 4 (right). However, this paper focuses only on the open-loop behavior of the utility's demand response control system in the time interval of a single price signal, i.e., less than 5 minutes. The longer term closed-loop behavior of the utility demand response control system will be examined in future work.

The numerical experiments were conducted in three study cities located in the continental United States. Seattle is in a northern cool climate and is chosen for mild winters amenable to demand response using heat-pumps and mild summers for which demand response will be very limited. Phoenix and Miami are in southern hot climates, the former with dry summer conditions and the latter with humid conditions, both of which can challenge air-conditioning demand response. he detailed simulation models and source code are provided 
in Appendix B of [28].

\subsection{Residential Model}

The reference house design is a two-storey structure with a crawlspace and an attic. The space conditioning unit is an all-electric direct expansion heatpump with a single speed compressor and fan, which are sized according to the design conditions for the study cities, Seattle, Miami and Phoenix. Depending on the city, the homes are expected to consume between 18 and 21 MWh annually based on the local energy code. Widely varying contribution to space conditioning costs for heating and cooling are expected based on the

locale. Thermostat setback schedules are employed. Service hotwater is provided by electric resistance coils. The thermal parameters of the reference house are derived by GridLAB-D [28] using a standard second-order thermal response [30].

The basic house thermal parameters are chosen so that homes comply with the performance-based energy code, as allowed for by the 2012 International Energy Conservation Code (IECC) [31] and summarized in Table 1. These values were chosen to ensure that simulations results are for typical homes in the locales and are most likely to participate in demand response programs that utilities deploy. Where necessary GridLAB-D implements ASHRAE-compliant system sizing methods to determine the capacity and efficiency of heating, cooling and ventilation systems.

Internal gains are based on hourly ELCAP load shapes [32]. Because the ELCAP load shape data does not include subhourly fluctuations, the simulations assume that internal gains are constant for any given 5-minute interval during which the response to a change in price is considered. Modifications to the 1993 ELCAP load shapes are necessary to bring the magnitudes up to date based on the 2013 Residential Building Stock Assessment (RBSA) load surveys by the Northwest Energy Efficiency Alliance (NEEA) as shown in Table 2 [33].

The residential occupancy schedule is chosen for a typical dual-income family with 2 children in school, as shown in Table 3. The occupancy comfort settings 
are based on the settings observed in the Columbus demonstration. The indoor air temperature setpoints are normally on a setback schedule. The simulation studies employ setback schedules suitable for a two-worker middle-income family with children in public school, as shown in Table 3.

\subsection{Electricity Prices}

The customer cost of electricity varies according to the tariff employed to compute electricity price. Three tariffs are used in this study, one for customers paying conventional fixed energy price, one for customers paying time-of-use prices, and one for customer paying real-time prices.

The tariffs used in the study differ from those extant in the study cities to facilitate direct comparison of regional response signals with otherwise comparable characteristics. For example, in Seattle the average price of electricity was $9.6 \mathrm{c} / \mathrm{kWh}$ in August 2014. Customers in Miami paid around $12.1 \mathrm{c} / \mathrm{kWh}$ in the summer of 2014. Customers in Phoenix paid an inclining block rate in 2014. However, for the purpose of making results comparable the same tariff structures are used for all three study cities with price adjustments to maintain revenue neutrality.

\section{Results and Discussion}

The individual houses are simulated using GridLAB-D [28] in the four study cases for fixed prices, time-of-use prices with and without demand response, and real-time prices with and without demand response for both the transactive thermostat design and the new thermostat design. In the case of TOU homes, the response results from the change of setpoint from an occupancy schedule to a tariff schedule. In the case of the RTP homes the response results from the change from a $1^{\circ} \mathrm{F}\left(0.6^{\circ} \mathrm{C}\right)$ deadband around each setpoint to the $\pm \Delta P / K$ comfort setpoint offset from the heating or cooling setpoints, where $\Delta P$ is the normalized price differential $\left(P_{C}-P_{A}\right) / P_{D}$.

The energy cost impacts are shown in Figure 5. The most significant impacts are in winter. This is partly due to the judicious use of auxiliary heating in the 
responsive thermostats. But significant consumer cost savings are observed in all cases where demand response is a significant potential resource.

The discomfort degree hours for cooling and heating are obtained by computing the time-integral of indoor air temperature above (cooling) and below (heating) the maximum and minimum allowable temperatures. In the case of the fixed and TOU homes this range is $T_{C}+\frac{1}{2} D$ and $T_{H}-\frac{1}{2} D$, respectively. For the RTP and new thermostat homes it is $T_{C}+3 / K$ and $T_{H}-3 / K$, respectively.

The performance evaluation simulations are run with nominal demand response, i.e., for $\mathrm{TOU}$ a $2^{\circ} \mathrm{F}\left(1.1^{\circ} \mathrm{C}\right)$ setback schedule that coincides with the tariff schedule, and for RTP comfort gain settings for night, home, and away of $K=1.0,1.5$, and 0.5 , respectively.

The energy use impacts are shown in Figure 6. The TOU demand response shows a reduction in energy consistent with customers who change their thermostats from the unresponsive occupancy-driven setpoint schedules to responsive tariff-driven setpoint schedules. These results are consistent with those of other studies of TOU demand response [7].

The RTP results for heating shows a very significant energy use reduction but cooling results are mixed and modest in comparison. It should be noted that increases in energy consumption were also observed in the Olympic and Columbus results, although the magnitude of the increase was much greater in the Olympic results because of an error in the auxiliary heating control that originated in the conventional thermostat retrofitted for TOU and RTP operations and persists in the fixed and TOU controllers in this study. The RTP controller is corrected and its operation does not reflect the errors present in the Olympic results.

In the Olympic study an increase in energy of about $16 \%$ was observed for heating conditions [15]. This increase is believed to be caused by the unnecessary use of auxiliary heating during thermostat set-up events in excess of $2^{\circ} \mathrm{F}(\approx$ $1.1^{\circ} \mathrm{C}$ ). To date there has been no attempt to rigorously study what the Olympic results would have been had the auxiliary heating control not be misapplied. It should be noted that this paper has completely corrected the auxiliary control 
problem only in the RTP and new thermostat, and the auxiliary heating can be engaged during thermostat set-up in the winter. In any case this result may provide initial evidence of what the Olympic study would have yielded had the auxiliary heating control been implemented correctly then.

The Columbus study also found increases in energy use in cooling conditions of about $1 \%$ when congestion pricing was extant. Decreases of about $5 \%$ were deduced when congestion pricing was not in effect [16]. Because congestion pricing typically expressed itself in short-term price volatility, the summer results are consistent with the observations from the Columbus study.

In general the heating energy use impacts of the new thermostat are similar to those of the RTP thermostat. However, the cooling energy use impacts of the new thermostat are approximately double those of the RTP thermostat. It is not clear exactly what is the root cause of this increase, but it is possibly related to so-called "round-trip" efficiency considerations that result from the increased use thermal storage as a proxy for electric energy storage [34]. These roundtrip efficiency impacts may be increased by the minimum 5 -minute runtimes under the new thermostat, which preferentially increases the amount of thermal storage being used for short-term events relative to long-term events.

The consumer comfort impacts are examined using two performance metrics. The heating/cooling relative setpoint errors are computed as the standard deviation of the air temperature with respect to the prevailing setpoint. The fixed and TOU setpoint errors are computed with respect to the deadband of $D=1^{\circ} \mathrm{F}$ $\left(\approx 0.6^{\circ} \mathrm{C}\right)$, so only air temperatures observed outside $\pm_{2}^{1}{ }^{\circ} \mathrm{F}\left(\approx \pm 0.3^{\circ} \mathrm{C}\right)$ are considered. Such errors occur each time the setpoint is changed either from a change in occupancy schedule or price change, which explains why the setpoint errors are relatively high for both fixed and TOU controls.

The RTP and new thermostat control setpoint errors shown in Table 4 account for the comfort setting $k=1.0$ and thus allow for larger fluctuations of the indoor air temperature, provided it does not go outside the consumer's comfort preference. Because the price signal is generated from a Gaussian distribution, we expect the RTP signal to deviate by more than $3 \sigma$ less than $1 \%$ of the time. 
The new thermostat can deviate more because of the increased probability of indoor air temperature overshoot. Such a deviation occurs less than $1 \%$ the time with the new thermostat.

We also apply a more sensitive evaluation of the comfort performance using the discomfort degree hour method, as shown in Figure 7. The results suggest that while the new thermostat is slightly less able to maintain the consumer's preferred comfort, it is very nearly as good as the RTP thermostat when compared to the TOU thermostat control strategy or indeed the conventional fixed thermostat.

A feeder-scale simulation of 100 homes in Phoenix is used to illustrate the open-loop response of the load to changes in the price signal. A sample of the output is shown in Figure 8. The result clearly illustrates how the new thermostat (blue) remedies the RTP thermostat drift problem (red) as they respond to the price signals (black). Note that the feeder load control is simulated as an open-loop control and thus the response gain $K$ is not affected by a market clearing process. Therefore any price above average results in load shedding and any price above average will result in load running. This will be addressed in future work when the bidding system is implemented to close the feeder load control loop.

\subsection{Principal Findings}

The simulations studies show that the new thermostat offers benefits to both consumers and utilities. The principal features of the new thermostat design are as follows.

No Aggregate Load Drift: The new thermostat eliminates the hysteresis arising from the deadband in the Schmitt trigger control element used in conventional, TOU and RTP thermostats. As a result the new thermostat does not exhibit an aggregate load drift behavior between price clearing events in the market.

Consumer Comfort Control: The new thermostat maintains satisfactory control of indoor air temperature. The new thermostat enhances the favor- 
able economic and thermal control characteristics of conventional, TOU and RTP thermostats. Most significant is the new thermostat allows consumers to specify a comfort preference for each occupancy mode, e.g., home/awake, night/sleep, away/work, and by extension any others the consumer might add.

Load shifting and Cost Savings: The new thermostat provides the desired energy shifting and cost savings properties required for real-time priceresponsive thermostats and enhances those found in the conventional and TOU thermostat, especially in the short-term response time intervals.

Demand Elasticity: During peak times, the new thermostat gives the entire residential load an energy demand elasticity between $10 \%$ to $25 \%$. Larger total house demand elasticities could be achieved if a similar control strategy were adopted for other thermostatic end-use load such refrigerators, freezers, water heaters, dish washers, clothes washers, and dryers.

Transactive Control Compatibility: The new thermostat's demand response implementation is consistent and compatible with that the RTP thermostat demand response design used in the Olympic and Columbus transactive control studies. Thus it can operate in the real-time distribution capacity auction system and can provide all the benefits associated with transactive systems, and particularly those environmental benefits associated with increased integration of renewable resources.

The most significant benefit arises from the overall impact of increased participation of demand response as a controllable resource in electric system operation. Demand response can be regarded as one of the most cost-effective intermittency mitigation resources available to grid operators, provided it can be actuated quickly and accurately [13] and given the right economic signals at the right time [35]. The results of this work suggests that with appropriately designed controls, residential thermostats can provide both of these key characteristics at scale and at relatively low cost. Indeed, it would seem that 
simpler and easier to use thermostat designs may indeed offer greater intermittent resource mitigation potential than more sophisticated and difficult to use thermostats.

\section{Conclusions}

This paper presents an evaluation the performance of a new control strategy for residential heating and cooling thermostats that support the transactive control system concept. The new thermostat outperforms conventional thermostats by providing significant fast-acting demand response resources and does so in a manner that is highly conducive to aggregate load control by utilities using realtime price signals. The new thermostat has all the features and advantages of real-time price (RTP) and time-of-use (TOU) thermostats and overcomes many disadvantages typically associated with them.

From the utility's perspective the new thermostat offers one very significant advantage over the other demand response thermostat designs. The new thermostat provides significantly better control tracking of the load for the price given. In particular, the heating/cooling load under control of the new thermostat will remain at the level associated with the price given for the entire duration of the pricing time-interval. Unlike conventional, TOU and RTP thermostats, which cause the total load to change when the deadband is exceeded, the new thermostat maintains the system load as dispatched until the new price is received. Thus the impact of the error is shifted from the utility where it cannot be addressed without resorting to more complex bid/response compensation/anticipation strategies to the consumer where its impact can be mitigated by the consumer's comfort setting.

\section{Acknowledgment}

This work was funded by the US Department of Energy's Pacific Northwest National Laboratory, located in Richland, Washington (USA). Pacific Northwest National Laboratory is operated by Battelle Memorial Institute for the US Deparment of Energy under Contract DE-AC05-76RL01830. 


\section{References}

\section{References}

[1] L.D. Kannberg, D.P. Chassin, J.G. DeSteese, S.G. Hauser, M.C. KintnerMeyer, R.G. Pratt, L.A. Schienbein, and M.W. Warwick. Gridwise ${ }^{\mathrm{TM}}$ : The benefits of a transformed energy system. PNNL Report No. 14396, Pacific Northwest National Laboratory, Richland, Washington. September 2003. URL http://arxiv.org/ftp/nlin/papers/0409/0409035.pdf.

[2] United States Federal Energy Regulatory Commission. Order no. 745 "demand response compensation in organized wholesale energy markets", March $152011 . \quad$ URL http://www.ferc.gov/EventCalendar/Files/20110315105757-RM10-17000.pdf.

[3] US Court of Appeals for the District of Columbia. Electric Power Supply Association v. Federal Energy Regulatory Commission, decided on May 23 2014. URL http://caselaw.findlaw.com/us-dc-circuit/1667561.html.

[4] J. B. Cardell, C. C. Hitt, and W. W. Hogan. Market power and strategic interaction in electricity networks. Resource and Energy Economics, 19(1):109-137, 1997.

[5] P. S. Moura and A. T. de Almeida. The role of demand-side management in the grid integration of wind power. Applied Energy, 87(8):2581 - 2588, 2010.

[6] D. Wang, S. Parkinson, W. Miao, H. Jia, C. Crawford, and N. Djilali. Online voltage security assessment considering comfort-constrained demand response control of distributed heat pump systems. Applied Energy, 96(0):104 - 114, 2012. Smart Grids.

[7] A. Faruqui and S. Sergici. Household response to dynamic pricing of electricity - a survey of the empirical evidence. Technical report, Brattle Group, February 2010. 
[8] R. Frank and B. Bernanke. Principles of microeconomics. McGrawHill/Irwin, New York, 2009.

[9] R.G. Smith. The contract net: A formalism for the control of distributed problem solving. In Proceedings of the 5th International Joint Conference on Artificial Intelligence - Volume 1, IJCAI77, pages 472-472, San Francisco, CA, USA, 1977. Morgan Kaufmann Publishers Inc.

[10] F.C. Schweppe, R.D. Tabors, J.L. Kirtley, H.R. Outhred, F.H. Pickel, and A.J. Cox. Homeostatic utility control. Power Apparatus and Systems, IEEE Transactions on, (3):1151-1163, 1980.

[11] F. Ygge, H. Akkermans, and A. Andersson. A multi-commodity market approach to power load management. In International Conference on Multi Agent Systems, July, pages 4-7, 1998.

[12] B. A. Huberman and S. H. Clearwater. A multi-agent system for controlling building environments. In ICMAS, pages 171-176, 1995.

[13] T. Broeer, J.C. Fuller, F. Tuffner, D.P. Chassin, and N. Djilali. Modeling framework and validation of a smart grid and demand response system for wind power integration. Applied Energy, 113:199-207, 2014.

[14] W.W. Hogan. Providing incentives for efficient demand response. FERC Docket No. EL09-68, October 29 2009. Attachment to Answer of EPSA. URL http://www.epsa.org/forms/uploadFiles/... 1227200000027.filename.FINALEPSAAnswertoDRS.pdf.

[15] D.J. Hammerstrom et al. Pacific Northwest GridWise testbed demonstration projects: Part I. Olympic Peninsula project. Technical Report 17167, Pacific Northwest National Laboratory, Richland WA, October 2007.

[16] S.E. Widergren et al. AEP Ohio gridSMART demonstration project realtime pricing demonstration analysis. Technical Report 23192, Pacific Northwest National Laboratory, March 2014. 
[17] V. Smith and L. Kiesling. A market-based model for ISO-sponsored demand response programs. A white paper prepared for the multi-client study, August 2005.

[18] E.D. Hausman and R.D. Tabors. The role of demand under scheduling in the California energy crisis. In The 37th Hawaii International Conference on System Sciences (HICSS-37), Hawaii, 2004.

[19] P. Cappers, C. Goldman, and D. Kathan. Demand response in u.s. electricity markets: Empirical evidence. Energy, 35(4):1526 - 1535, 2010. Demand Response Resources: the $\{\mathrm{US}\}$ and International Experience Demand Response Resources: the $\{$ US $\}$ and International Experience.

[20] F. Rahimi and A. Ipakchi. Demand response as a market resource under the smart grid paradigm. Smart Grid, IEEE Transactions on, 1(1):82-88, 2010.

[21] N. Lu. An evaluation of the hvac load potential for providing load balancing service. Smart Grid, IEEE Transactions on, 3(3):1263-1270, Sept 2012.

[22] J. Kondoh, N. Lu, and D.J. Hammerstrom. An evaluation of the water heater load potential for providing regulation service. Power Systems, IEEE Transactions on, 26(3):1309-1316, Aug 2011.

[23] D.S. Callaway. Tapping the energy storage potential in electric loads to deliver load following and regulation, with application to wind energy. Energy Conversion and Management, 50(5):1389 - 1400, 2009.

[24] S. Parkinson, D. Wang, Crawford C, and N. Djilali. Comfort-constrained distributed heat pump management. Energy Procedia, 12(0):849 - 855, 2011. The Proceedings of International Conference on Smart Grid and Clean Energy Technologies (ICSGCE 2011.

[25] S. Stoft. Power Systems Economics. IEEE Press, 2002. 
[26] K. Subbarao, J.C. Fuller, K. Kalsi, A. Somani, R.G. Pratt, S.E. Widergren, and D.P. Chassin. Transactive control and coordination of distributed assets for ancillary services. Technical report, Pacific Northwest National Laboratory (PNNL), Richland, WA (US), 2013.

[27] D.P. Chassin, Y. Sun, and A. Somani. Optimization of customer subscription rates to electric utility tariffs. In 48th Hawaii International Conference on System Sciences (HICSS). IEEE, January 2015.

[28] D.P. Chassin, J.C. Fuller, and N. Djilali. Gridlab-d: An agent-based simulation framework for smart grids. Journal of Applied Mathematics, 2014(492320), 2014.

[29] K. Subbarao et al. Transactive control and coordination of distributed assets for ancillary services: Controls, markets and simulations. Technical Report number not available, Pacific Northwest National Laboratory, November 2014.

[30] K. Ogata. Modern control engineering. Prentice-Hall, 2010.

[31] IECC. International Energy Conservation Code, Chapter 4 - Residential Energy Efficiency, 2012.

[32] R.G. Pratt, C.C. Conner, B.A. Cooke, and E.E. Richman. Metered end-use consumption and load shapes from the elcap residential sample of existing homes in the pacific northwest. Energy and buildings, 19(3):179-193, 1993.

[33] B. Larson and L. Gilman and R. Davis and M. Logsdon, J. Uslan and B. Hannas and D. Baylon and P. Storm and V. Mugford and N. Kvaltine. Residential Building Stock Assessment: Metering Study. Technical Report E14-283, Northwest Energy Efficiency Alliance, April 282014.

[34] I. Beil, I.A. Hiskens, and S. Backhaus. Round-trip efficiency of fast demand response in a large commercial air conditioner. Energy and Buildings, 97:47-55, 2015. 
[35] V.L. Smith and L. Kiesling. Demand, not supply. Wall Street Journal, 20:13, 2003. 


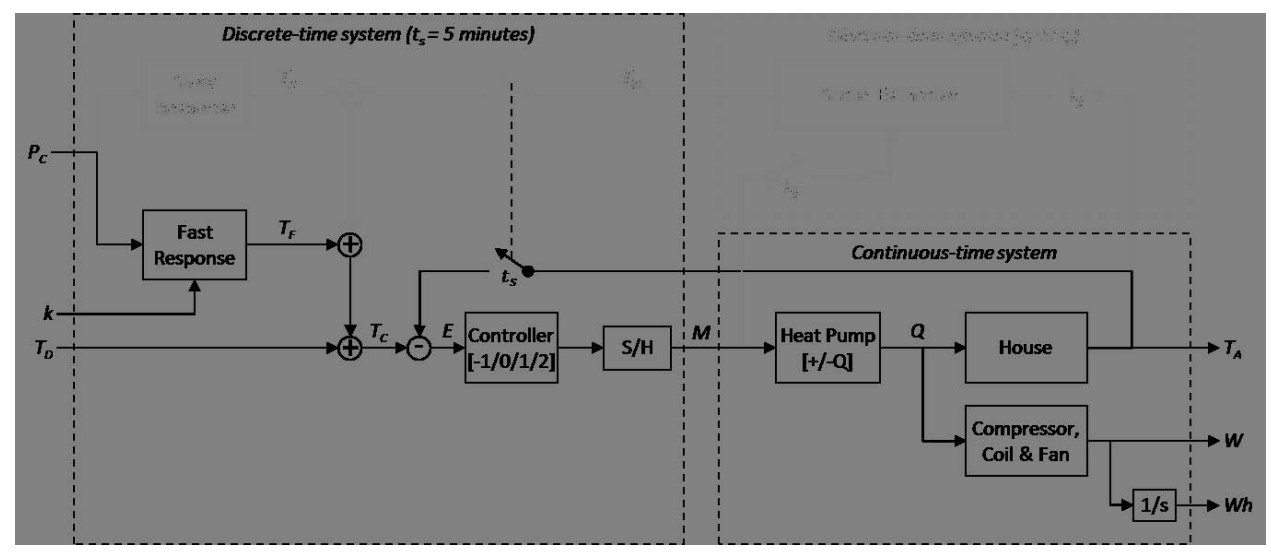

Figure 1: Proposed new thermostat design

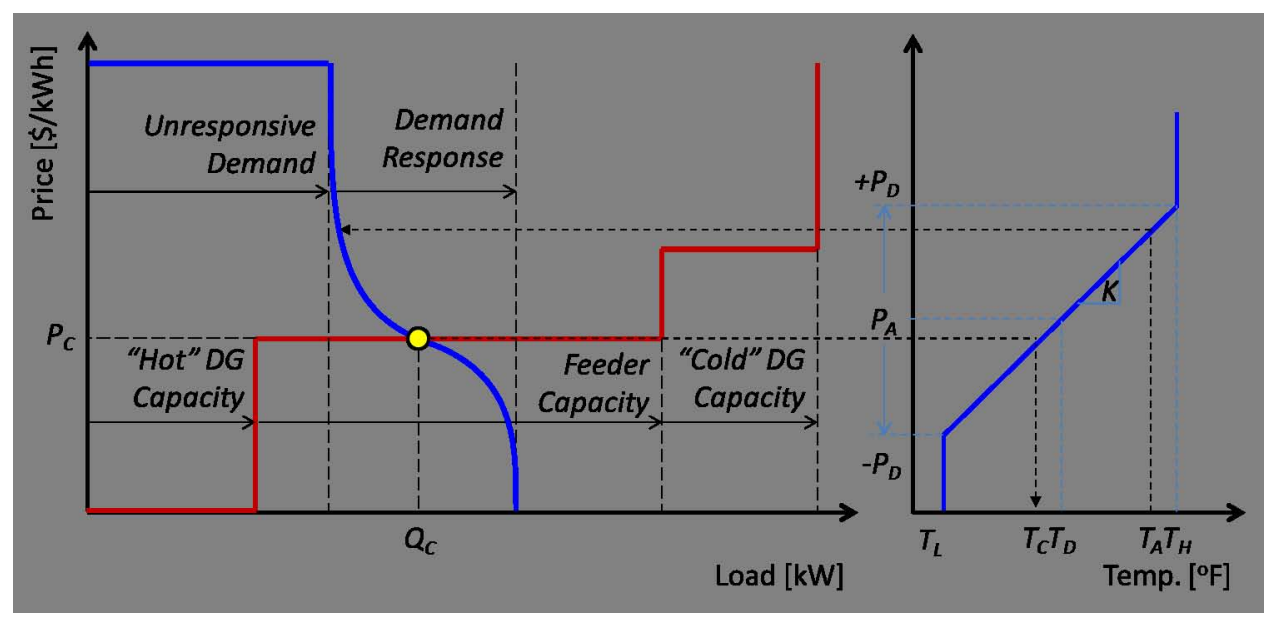

Figure 2: Capacity market clearing (left) and thermostat bid/set (right) mechanisms 

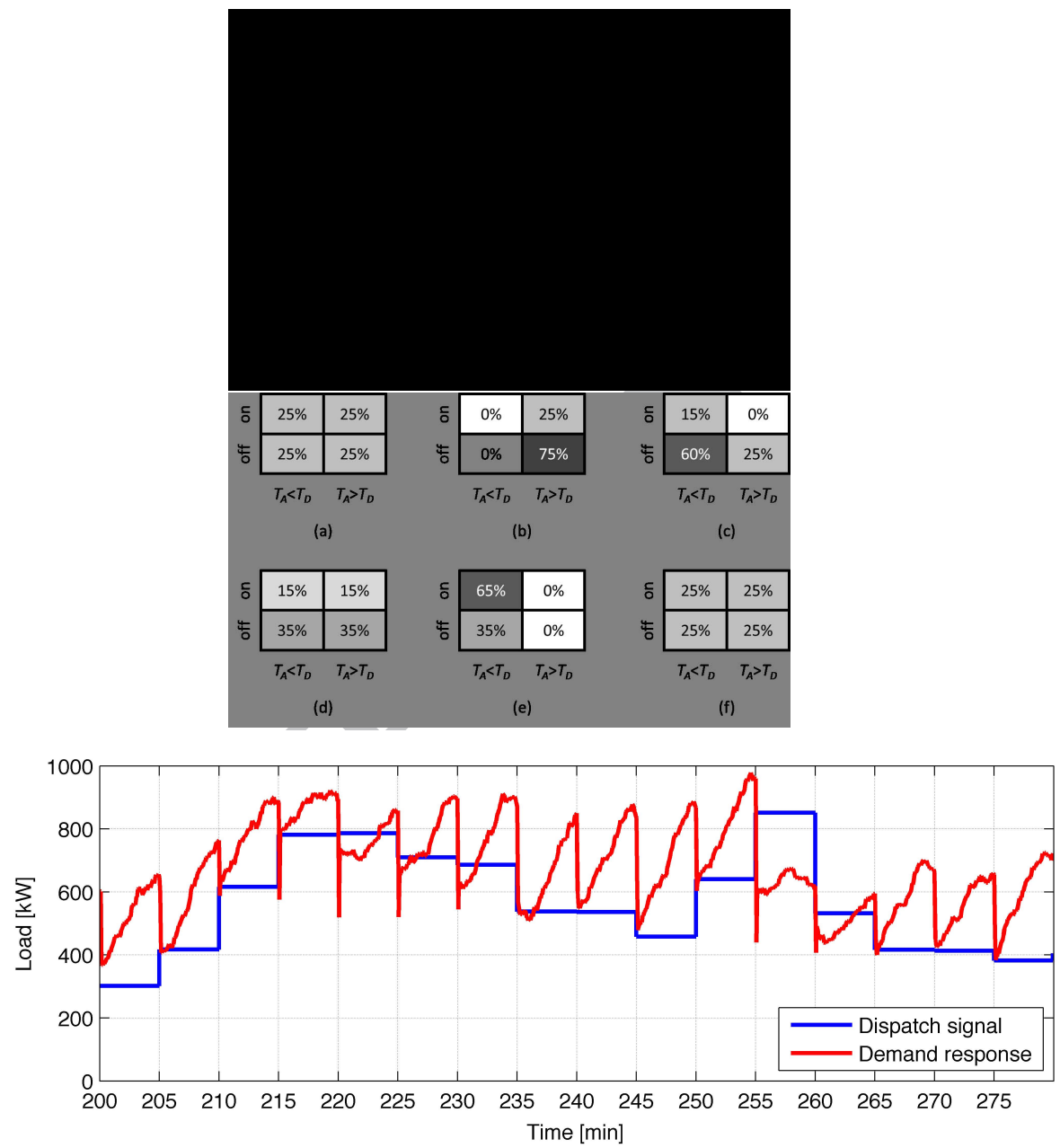

Figure 3: Thermostat state diversity evolution cause (top) and example (bottom) of demand response control drift (Data courtesy Jason Fuller, Pacific Northwest National Laboratory) 


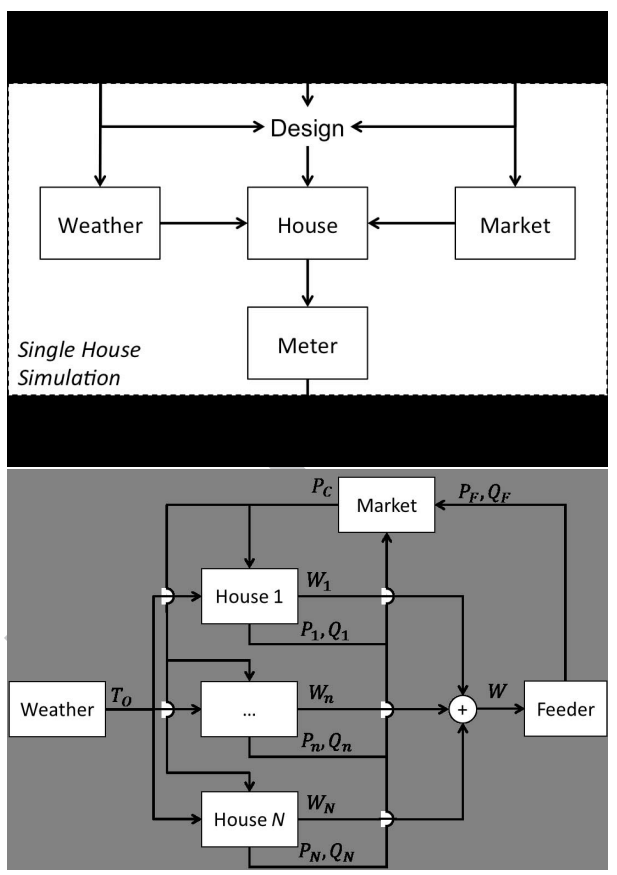

Figure 4: Single house simulation (left) and utility feeder simulation (right) structures 


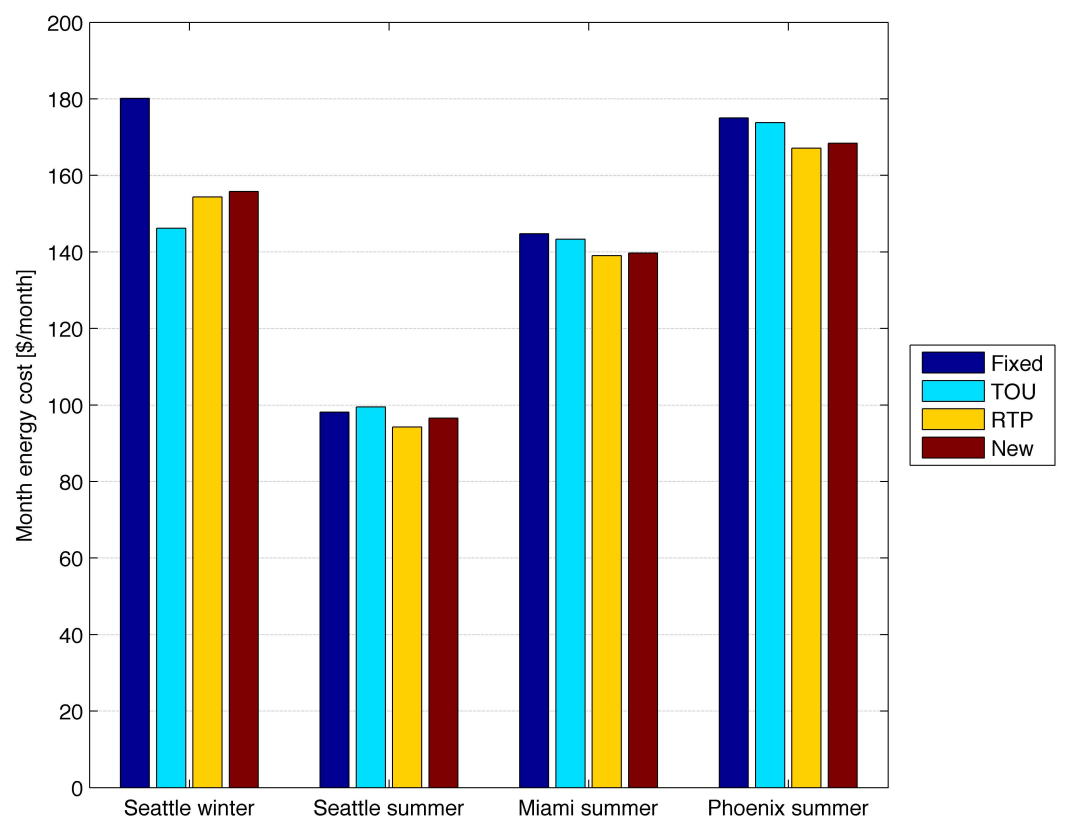

Fixed TOU RTP

\begin{tabular}{lrrrrrrr} 
& (\$/month $)$ & $(\$ /$ month $)$ & $(\%)$ & $\begin{array}{r}\text { RTP } \\
(\$ / \text { month })\end{array}$ & $(\%)$ & $\begin{array}{r}\text { New } \\
(\$ / \text { month })\end{array}$ & $(\%)$ \\
\hline Seattle winter & 180.1 & 146.2 & -18.8 & 154.4 & -14.3 & 155.8 & -13.5 \\
Seattle summer & 98.1 & 99.5 & +1.3 & 94.3 & -4.0 & 96.6 & -1.6 \\
Miami summer & 144.8 & 143.3 & -1.0 & 139.0 & -4.0 & 139.7 & -3.5 \\
Phoenix summer & 175.0 & 173.8 & -0.7 & 167.1 & -4.5 & 168.4 & -3.8 \\
\hline
\end{tabular}

Figure 5: Energy cost with demand response active 


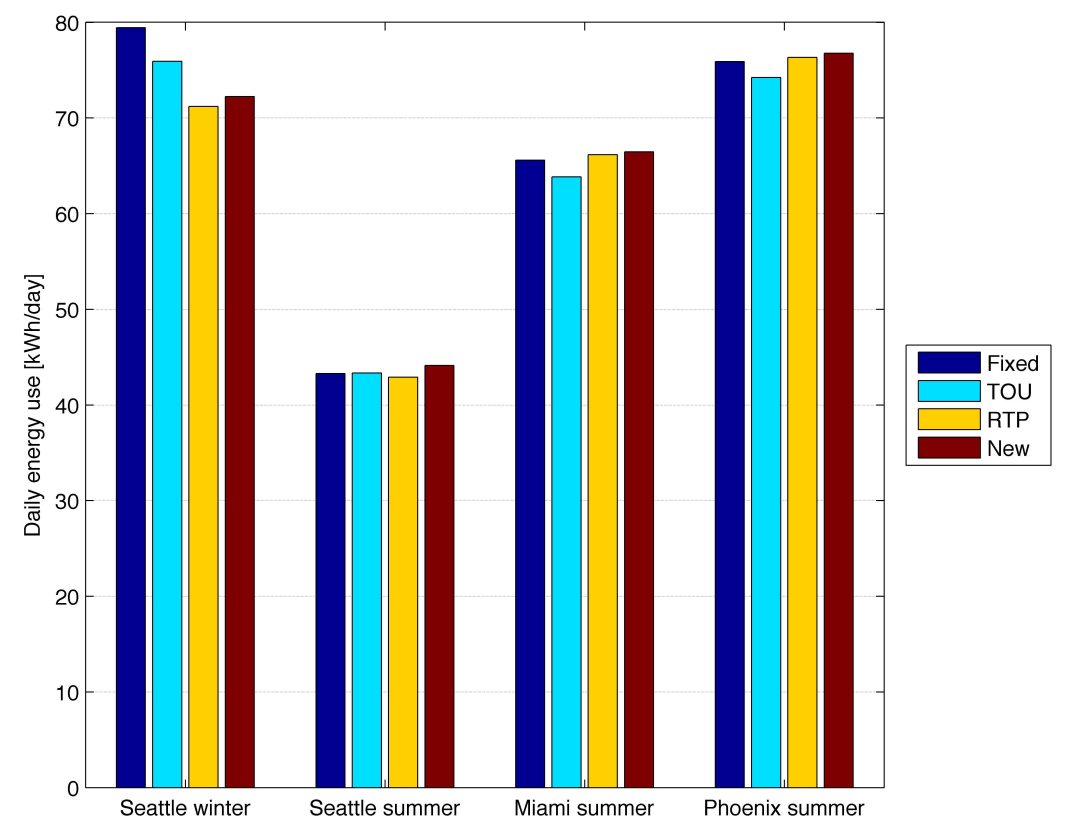

$\begin{array}{llll}\text { Fixed } & \text { TOU } & \text { RTP } & \text { New }\end{array}$

\begin{tabular}{lrrrrrrr} 
& $(\mathrm{kWh} /$ day $)$ & $(\mathrm{kWh} /$ day $)$ & $(\%)$ & $(\mathrm{kWh} /$ day $)$ & $(\%)$ & $(\mathrm{kWh} /$ day $)$ & $(\%)$ \\
\hline Seattle winter & 79.4 & 75.9 & -4.4 & 71.2 & -10.3 & 72.2 & -9.1 \\
Seattle summer & 43.3 & 43.3 & +0.1 & 42.9 & -0.9 & 44.1 & +2.0 \\
Miami summer & 65.6 & 63.8 & -2.7 & 66.2 & +0.9 & 66.5 & +1.3 \\
Phoenix summer & 75.9 & 74.2 & -2.2 & 76.3 & +0.6 & 76.8 & +1.2 \\
\hline
\end{tabular}

Figure 6: Energy use with demand response active 


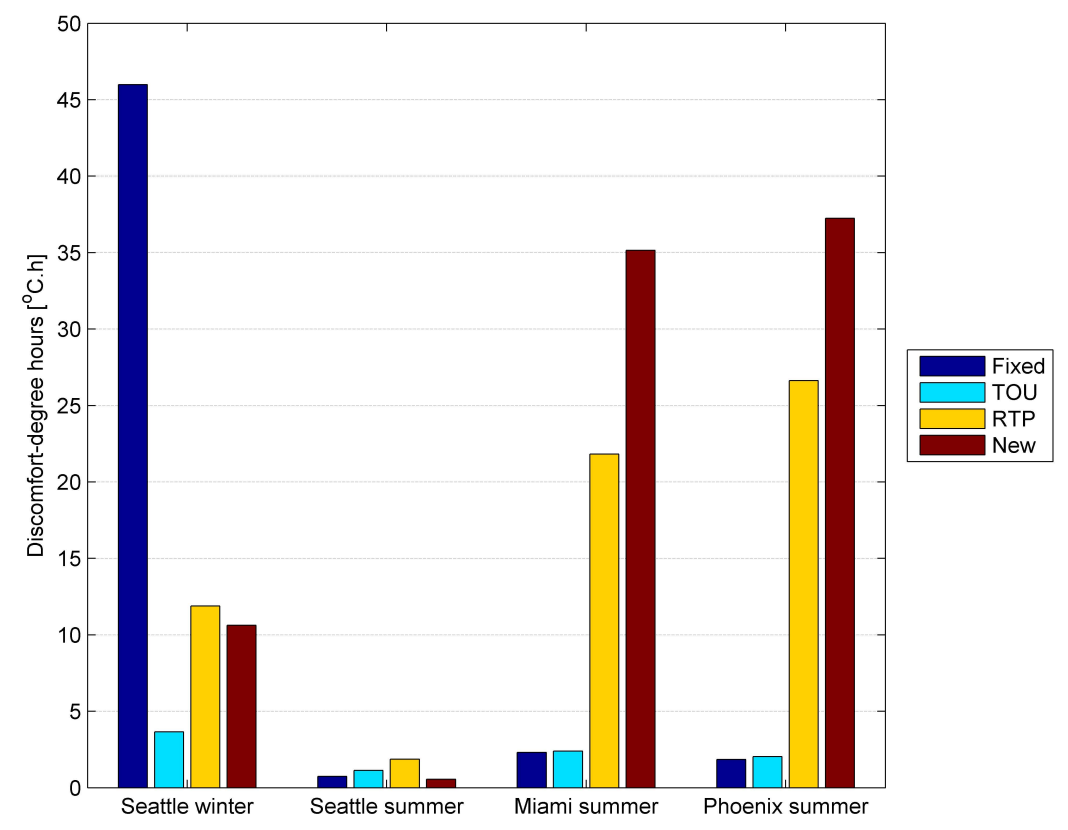

\begin{tabular}{lrrrr} 
& $\begin{array}{r}\text { Fixed } \\
\left({ }^{\circ} \mathrm{C} . \mathrm{h}\right)\end{array}$ & $\begin{array}{r}\text { TOU } \\
\left({ }^{\circ} \mathrm{C} . \mathrm{h}\right)\end{array}$ & $\begin{array}{r}\text { RTP } \\
\left({ }^{\circ} \mathrm{C} . \mathrm{h}\right)\end{array}$ & $\begin{array}{r}\text { New } \\
\left({ }^{\circ} \mathrm{C} . \mathrm{h}\right)\end{array}$ \\
\hline Seattle winter & 46 & 4 & 12 & 11 \\
Seattle summer & 1 & 1 & 2 & 1 \\
Miami summer & 2 & 2 & 22 & 35 \\
Phoenix summer & 2 & 2 & 27 & 37 \\
\hline
\end{tabular}

Figure 7: Heating and cooling discomfort degree hours $\left( \pm 0.6^{\circ} \mathrm{C}\right)$ 

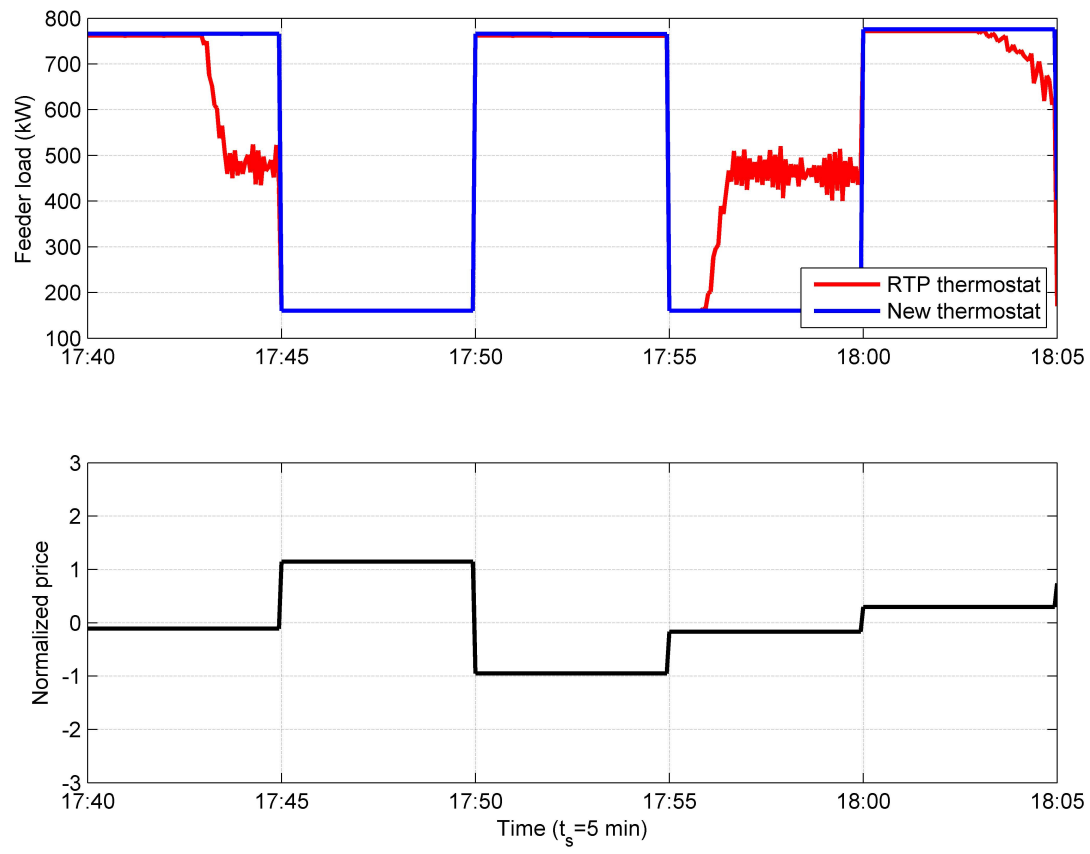

Figure 8: Feeder open-loop load control response to price 
Table 1: House design parameters

\begin{tabular}{lrrr} 
Parameter & Seattle & Miami & Phoenix \\
\hline Floor area $\left(\mathrm{m}^{2}\right)$ & 223 & 223 & 223 \\
Envelope conductance $\left(\mathrm{W} /{ }^{\circ} \mathrm{C}\right)$ & 283 & 227 & 227 \\
Indoor air heat capacity $\left(\mathrm{kJ} /{ }^{\circ} \mathrm{C}\right)$ & 1931 & 1735 & 1735 \\
Building mass surface conductivity $\left(\mathrm{W} /{ }^{\circ} \mathrm{C}\right)$ & 5884 & 5884 & 5884 \\
Building mass heat capacity $\left(\mathrm{kJ} /{ }^{\circ} \mathrm{C}\right)$ & 7828 & 7033 & 7033 \\
\hline
\end{tabular}

Table 2: ELCAP loadshapes update with RBSA results

\begin{tabular}{lrrrrrr} 
End-use & $\begin{array}{r}\text { ELCAP } \\
(\mathrm{kWh} / \mathrm{d})\end{array}$ & $\begin{array}{r}\text { Winter } \\
\text { RBSA } \\
(\mathrm{kWh} / \mathrm{d})\end{array}$ & $\begin{array}{r}\text { Change } \\
(\mathrm{pu})\end{array}$ & $\begin{array}{r}\text { ELCAP } \\
(\mathrm{kWh} / \mathrm{d})\end{array}$ & $\begin{array}{r}\text { Summer } \\
\text { RBSA } \\
(\mathrm{kWh} / \mathrm{d})\end{array}$ & $\begin{array}{r}\text { Change } \\
(\mathrm{pu})\end{array}$ \\
\hline Lights & See note $(1)$ & 3.62 & - & - & 2.75 & - \\
Plugs & 14.47 & 21.71 & 1.50 & 11.00 & 16.50 & 1.50 \\
Dishwasher & 0.36 & 0.60 & 1.66 & 0.31 & 0.60 & 1.95 \\
Freezer & 3.68 & 1.40 & 0.38 & 5.03 & 1.91 & 0.38 \\
Refrigerator & 3.90 & 1.68 & 0.43 & 4.60 & 1.98 & 0.43 \\
Microwave & See note $(2)$ & 0.17 & - & - & 0.14 & - \\
Range & 1.43 & 0.80 & 0.56 & 1.14 & 0.64 & 0.56 \\
Waterheater & 14.34 & 8.03 & 0.56 & 11.21 & 6.28 & 0.56 \\
Clotheswasher & 0.31 & 0.15 & 0.50 & 0.28 & 0.14 & 0.50 \\
Dryer & 3.12 & 2.00 & 0.64 & 2.56 & 1.64 & 0.64 \\
\hline
\end{tabular}

Notes:

(1) In ELCAP lights and plugs are combined

(2) In ELCAP all cooking is combined 
Table 3: Occupancy and thermostat setpoint schedule

\begin{tabular}{|c|c|c|c|c|c|}
\hline Occupancy & Weekday & Weekend & $\begin{array}{c}\text { Heating } \\
\left({ }^{\circ} \mathrm{C}\right)\end{array}$ & $\begin{array}{c}\text { Cooling } \\
\left({ }^{\circ} \mathrm{C}\right)\end{array}$ & $\begin{array}{c}\text { Comfort } \\
\$ /{ }^{\circ} \mathrm{C}\end{array}$ \\
\hline Night & $20: 00-6: 00$ & $23: 00-7: 00$ & 20 & 24 & 0.56 \\
\hline Home & $\begin{array}{c}6: 00-8: 00 \\
18: 00-22: 00\end{array}$ & $7: 00-23: 00$ & 22 & 26 & 0.83 \\
\hline Away & $8: 00-18: 00$ & - & 19 & 27 & 0.28 \\
\hline
\end{tabular}

Table 4: Heating and cooling relative setpoint errors

\begin{tabular}{|c|c|c|c|c|c|c|c|c|}
\hline & \multicolumn{4}{|c|}{ Heating } & \multicolumn{4}{|c|}{ Cooling } \\
\hline & $\begin{array}{r}\text { Fixed } \\
(\%)\end{array}$ & $\begin{array}{r}\text { TOU } \\
(\%)\end{array}$ & $\begin{array}{r}\text { RTP } \\
(\%)\end{array}$ & $\begin{array}{r}\text { New } \\
(\%)\end{array}$ & $\begin{array}{r}\text { Fixed } \\
(\%)\end{array}$ & $\begin{array}{r}\text { TOU } \\
(\%)\end{array}$ & $\begin{array}{r}\text { RTP } \\
(\%)\end{array}$ & $\begin{array}{r}\text { New } \\
(\%)\end{array}$ \\
\hline Seattle winter & 6.0 & 1.2 & 0.4 & 0.2 & 0.0 & 0.0 & 0.0 & 0.0 \\
\hline Seattle summer & 0.5 & $<0.1$ & 0.2 & 0.3 & 0.3 & 0.3 & 0.0 & 0.0 \\
\hline Miami summer & 0.0 & 0.0 & 0.0 & 0.0 & 0.7 & 0.9 & $<0.1$ & 0.2 \\
\hline Phoenix summer & 0.0 & 0.0 & 0.0 & 0.0 & 0.8 & 1.1 & 0.2 & 0.3 \\
\hline
\end{tabular}

